
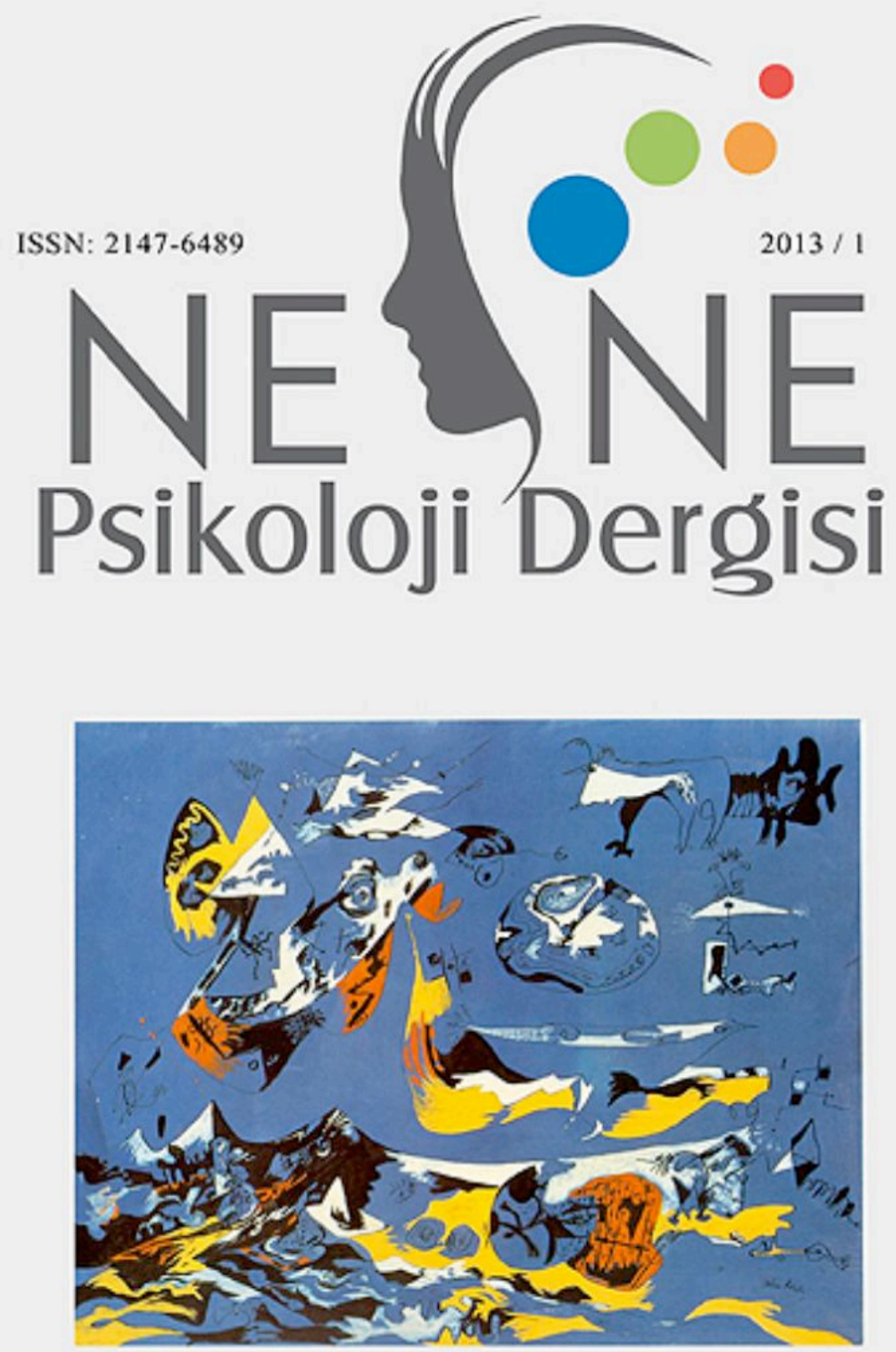

www.nesnedergisi.com 


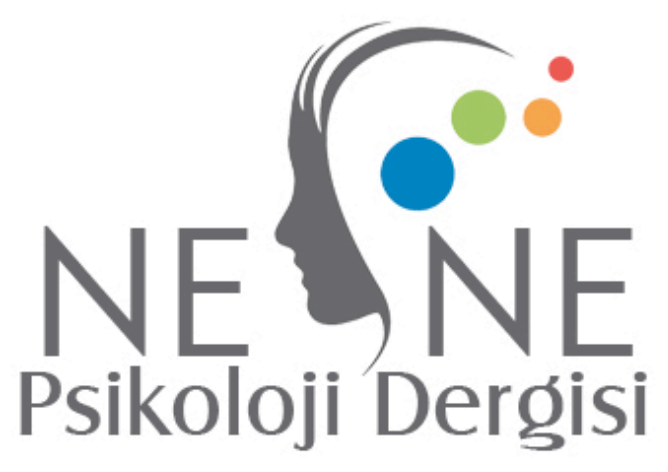

Nesne Dergisi'ne gönderilecek yazıların özgün olması ve evrensel bilime katkıda bulunması beklenmektedir. Bununla birlikte, bilim insanlarını tanıtan, yeni etkinlikleri veya yayınları duyuran yazılara ve röportajlara da yer verilir.

Makalelerin Nesne'de yayımlanabilmesi için, daha önce bir başka yerde yayımlanmamış ve yayımlanmak üzere kabul edilmemiş olması gerekir. Daha önce sempozyum, kongre v.b bilimsel toplantılarda sunulmuş; ancak yayımlanmamış bildiriler ile lisans ve lisansüstü tezlerden üretilmiş çalışmalar da yayına kabul edilir.

Nesne, Yaz/Haziran ve Kış/Aralık olmak üzere yılda iki sayı olarak yayımlanır. Her yılın sonunda derginin yıllık dizini hazırlanır ve Kış sayısında yayımlanır. Dergi, Yayın Kurulu tarafından belirlenen yurt içi ve dışındaki kütüphanelere, uluslararası indeks kurumlarına ve abonelere yayımlandığı tarihten itibaren bir ay içerisinde gönderilir.

Nesne'de yayımlanması kabul edilen yazıların telif hakkı Nesne Psikoloji Dergisi'ne devredilmiş sayılır. Yayımlanan yazılardaki görüşlerin sorumluluğu yazarlarına aittir. Dergideki yazı ve fotoğraflardan kaynak gösterilerek alıntı yapılabilir.

Nesne'nin yayın dili Türkçe ve İngilizce'dir.

\section{About NESNE}

Articles to be sent to Nesne Psychology Journal are expected to be original and to contribute to universal science. Moreover, the journal gives place to articles and interviews that introduce scientists, artists and publications.

In order for an article to be published in Nesne, it is necessary for it not to be published anywhere before or accepted to be published. Papers that have been presented in a symposium or conference before but have not been published and studies produced from undergraduate thesis, master's thesis and dissertation are also welcomed.

Nesne is published two times a year: Summer/June and Winter/December. At the end of each year, the index of the journal is prepared and punlished in Winter issue. The journal is sent to the libraries in the country and abroad, international index institutions and subscribes by the editorial board within a month after publication. 


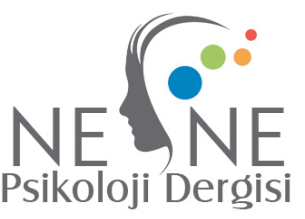

ISSN: 2147- 6489 Sayı/Number:1 Yaz/Spring 2013

İmtiyaz Sahibi / Publisher

Sanat ve Dil Araştırmaları Enstitüsü

Genel Yayın Yönetmeni / Editor in Chief

Sezin ANDİÇ

Elektronik Yayın Yönetimi ve Tasarım / Web Management and Design

Eşref YARIMCA

Düzelti / Revision

Melis ÇELIK, Selin KÖKSAL ARAÇ, İbrahim YİĞİT, Dürdane KOCABAY

GÜMÜŞTEN, Begüm DEMİR, Cihat

ÇELIKK, Fatma YAŞIN

Online Haber Editörü / Online News Editor

Gizem Köksal

Kapak Resmi / Cover

Jackson Pollock, Blue (Moby Dick)

Yazı ișleri Müdürü / Managing Editor

Sezin ANDİÇ

Yazışma Adresi / Correspondence Address

Sezin ANDİÇ, Ankara Üniversitesi, Dil ve Tarih-Coğrafya Fakültesi, Psikoloji Bölümü, Sihhıye/Ankara, Türkiye

www.nesnedergisi.com // bilgi@nesnedergisi.com 


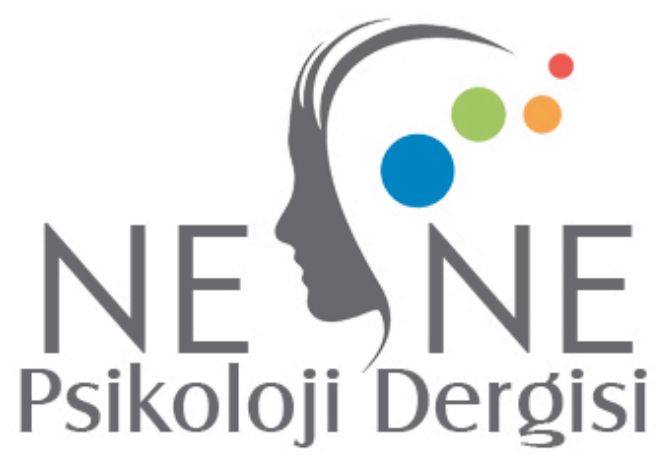

YAYIN KURULU / EDITORIAL BOARD

Doç. Dr. Banu YILMAZ (Ankara Üniversitesi)

Doç. Dr. Belma BEKÇİ (Okan Üniversitesi)

Doç. Dr. Derya HASTA (Ankara Üniversitesi)

Doç. Dr. Michelle ADAMS (Bilkent Üniversitesi)

Yrd. Doç. Dr. Mediha KORKMAZ (Ege Üniversitesi)

Öğr. Gör. Zuhal YENIÇERİ (Başkent Üniversitesi)

Araş. Gör. Ebru AKÜN (Ankara Üniversitesi)

Araş. Gör. Matthew D. MARRERO (University of New Orleans)

Araş. Gör. Özge AKBALIK (Ankara Üniversitesi) 


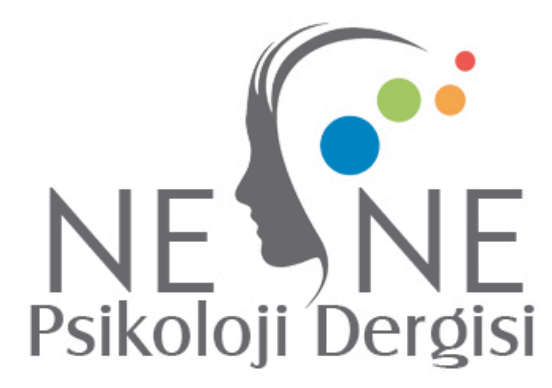

HAKEM VE DANIŞMA KURULU / REFEREE AND ADVISORY BOARD

Prof. Dr. Aylin KÜNTAY (Koç Üniversitesi)

Prof. Dr. Ayşegül DURAK BATIGÜN (Ankara Üniversitesi)

Prof. Dr. Ayşen GÜRE (Ankara Üniversitesi)

Prof. Dr. Doğan KÖKDEMİR (Başkent Üniversitesi)

Prof. Dr. Hamit COŞKUN (Abant İzzet Baysal Üniversitesi)

Prof. Dr. Gülsen ERDEN (Ankara Üniversitesi)

Prof. Dr. Melike SAYIL (Hacettepe Üniversitesi)

Prof. Dr. Nurhan ER (Ankara Üniversitesi)

Prof. Dr. Robert LAIRD (University Of New Orleans)

Prof. Dr. Selim HOVARDAOĞLU (Ankara Üniversitesi)

Prof. Dr. Sezen ZEYTİNOĞLU (İzmir Üniversitesi)

Prof. Dr. Şennur KIŞLAK (Ankara Üniversitesi)

Prof. Dr. Tevfika TUNABOYLU İKİZ (İstanbul Üniversitesi)

Prof. Dr. Zehra YAŞIN DÖKMEN (Ankara Üniversitesi)

Doç. Dr. Ayda BÜYÜKŞAHİN SUNAL (Ankara Üniversitesi)

Doç. Dr. Ersin KUŞDİL (Uludağ Üniversitesi)

Doç. Dr. Nilhan SEZGİN (Ankara Üniversitesi)

Doç. Dr. Orçun YORULMAZ (Uludağ Üniversitesi)

Yrd. Doç. Dr. Ekrem DÜZEN (İzmir Üniversitesi)

Yrd. Doç. Dr. Hüseyin BOYACI (Bilkent Üniversitesi)

Yrd. Doç. Dr. Okan ÇIRAKOĞLU (Başkent Üniversitesi)

Yrd. Doç. Dr. Sema KARAKELLE (İstanbul Üniversitesi)

Yrd. Doç. Dr. Özden YARIMCA (Nevşehir Üniversitesi)

Dr. Oğuz YURTTADUR (Selçuk Üniversitesi)

Öğr. Gör. Banu ELMASTAŞ DİKEÇ (Uludağ Üniversitesi)

Psk. Levent Bekir TELLİ (Çukurova Üniversitesi) 


\section{Değerli Okuyucularımız,}

Nesne Psikoloji Dergisi olarak ilk sayımızla karşınızdayız. İlk sayımızın kapağını Jackson Pollock'un Blue (Moby Dick) isimli eseri süslüyor. Bu eserin, dergimizi çok güzel ifade ettiğini düşünüyoruz. Bir nesnenin küçük bir kısmını bölerek bakarsanız o nesneyi olduğundan daha farklı algılarsınız. Bütün ise onu oluşturan parçalardan daha fazlasıdır ve parçaların daha farklı algılanmasını sağlar. Diğer taraftan, insanın çeşitli uyarımları ve daha önceki yaşantılarının da etkisiyle nesneler ve nesnelerin nitelikleri anlamlı hale getirilerek tanınır ve o nesneye yönelik algı oluşur. Moby Dick isimli bu resimdeki figürlere parça parça baktığınızda içerisinde bulunduğunuz duygu durumu algıladıklarınızı etkileyebilir; resmin bütününe baktığınızda ise algılayacaklarınız farklılaşabilir. Tıpkı Nesne Psikoloji Dergisi'ni oluşturan her bir yazının kendi başına da değerliyken diğer yazılarla birlikte Nesne içerisinde yer aldığında ona yüklenecek anlamın ve değerin de artacak olması gibi...

Nesne'yi uzun vadede diğer dergilerden ayıracak olan belki de en önemli özelliği, tezlerden oluşturulacak yayınlara öncelik vermesi olabilir. Tez yazma süreci oldukça zorlu ve yorucu bir süreçtir. Aşırı iş yoğunluğu, zaman yetersizliği gibi birçok nedenden dolayı makale yayınları sürekli gecikmekte hatta çoğu tez, makaleye dönüştürülmemektedir. Diğer taraftan makalelerin erişilebilirliği tezlere oranla çok daha kolaydır. Özellikle yurtdışındaki bilim insanlarının, Türkiye'de yazılan bir teze ulaşmaları oldukça güçtür. Bu nedenle çalışmaların çoğu geniş çevrelere ulaşamamaktadır. Her biri psikoloji bilimine katkıda bulunmaya aday bu eserlerin bir dergide makale olarak yayımlanmasıyla, tezlerin bilim dünyasına katkılarının doğrudan artacağına inanıyoruz.

Psikolojinin klinik, gelişim, sosyal, endüstri ve örgüt psikolojisi, deneysel psikoloji ve psikometri olmak üzere bütün alanlarından özgün çalışmaların yayıma kabul edildiği Nesne'de, lisans, yüksek lisans ve doktora tezlerinden üretilen yayınlara öncelikli olarak yer verilecektir. Ayrıca dergide, bilim insanlarından gelen kuramsal, uygulamalı ve ayrıca disiplinler arası çalışmalar da yayımlanacaktır. Bununla birlikte, bilim insanlarını tanıtan, yeni etkinlikleri veya yayınları duyuran yazılara ve röportajlara da yer verilecektir. Derginin temel amacı, genç bilim insanlarının psikoloji bilimine olan katkılarını arttırmaktır.

Nesne'nin sizlerle tanışmasında birçok kişinin ve kurumun katkısı oldu. İlk sayımızda makaleleri ve görüşleri ile dergimize katkıda bulunan değerli yazarlarımıza ve hakemlerimize minnettarız. Ankara'dan, Konya'dan, Adana'dan, Nevşehir'den, Bursa'dan, İzmir'den, İstanbul'dan ve New Orleans, Londra, Moskova gibi dünyanın farklı bölgelerinden dergimize çeşitli vasıtalarla katkıda bulunan birçok isme de huzurlarınızda teşekkür ediyoruz. 


\section{NESNE YAZIM VE YAYIN ILLKELERİ}

\section{Amaç ve Kapsam}

Nesne Psikoloji Dergisi'nde (NPD) ağırlıklı olarak lisans, yüksek lisans ve doktora tez makalelerine yer verilmektedir. Ayrıca görgül araştırma ve derleme türü yayınlara da (en son literatürü kapsamlı bir şekilde kapsayan yazılar ve olgu sunuları) yer verilebilmektedir. Tüm yazılar Amerikan Psikologlar Birliği tarafından yayınlanan 'Publication Manual of American Psychological Association (5. Bask1), 2001' adlı kitapta belirtilen yazım ilkelerine uygun olarak yazılmalıdır. Kaynakça yazımındaki yanlışlık ve eksikliklerin en aza indirilmesi ile ilgili olarak http://dr-editor.com/ adresinden yararlanılması yazarlarımıza önerilir.

Psikolojinin klinik, gelişim, sosyal, endüstri ve örgüt psikolojisi, deneysel psikoloji ve psikometri olmak üzere bütün alanlarından özgün çalışmaların yayıma kabul edildiği Nesne'de, lisans, yüksek lisans ve doktora tezlerinden üretilen yayınlara öncelikli olarak yer verilecektir. Ayrıca dergide, bilim insanlarından gelen kuramsal, uygulamalı ve ayrica disiplinler arası çalışmalar da yayımlanacaktır. Bununla birlikte, bilim insanlarını tanıtan, yeni etkinlikleri veya yayınları duyuran yazılara ve röportajlara da yer verilecektir. Derginin temel amacı, genç bilim insanlarının psikoloji bilimine olan katkılarını arttırmaktır.

\section{Yazıların Değerlendirilmesi}

Nesne Psikoloji Dergisi'ne gönderilen yazılar, önce editörce dergi ilkelerine ve yazım kurallarına uygunluk açısından incelenir. Uygun görülen yazılar, Yayın Kurulu'na iletilir. Yayın Kurulu, gelen yazının içeriğini inceler, makaleyi ilgili alanda iki hakeme gönderir. Yayın Kurulu, gelen hakem raporlarına göre yazının yayımlanıp, yayımlanmayacağına karar verir. Yayın Kurulu tarafından, yayımlanmasına karar verilen yazılar, editörlerce yayın sırasına alınır ve yazarlara bilgi verilir.

Nesne Psikoloji Dergisi'nde yayımlanması kabul edilen yazıların telif hakkı Nesne Psikoloji Dergisi'ne devredilmiş sayılır. Yayımlanan yazılardaki görüşlerin sorumluluğu yazarlarına aittir.

\section{Yayın Dili}

Nesne Psikoloji Dergisi’nin yayın dili Türkçe ve İngilizce'dir.

\section{Genel İlkeler}

1. Dergiye gönderilecek yazılar, A4 boyutlarında beyaz kağıda üst, alt, sağ ve sol boşluk 2,5 cm. Birakılarak (16 x 24,7'lik alana)Microsoft Word programında Times New Roman yazı tipinde 12 punto ve 1,5 satır aralığıyla, düz metin olarak yazılmalıdır.

2. Yazılarda Türk Dil Kurumu'nun yazım kılavuzu dikkate alınmalı, yabancı sözcükler yerine olabildiğince Türkçe sözcükler kullanılmalıdır. Türkçede yaygın olarak kullanılmayan 
sözcükler yazıda kullanılırken ilk geçtiği yerde yabanc1 dildeki karşılığı parantez içinde verilmelidir (Türkçe ve İngilizce).

3. Yazılar başlık, özet (Türkçe ve İngilizce), anahtar kelimeler, ana metin, kaynaklar, ekler, tablolar, şekil başlıkları, şekiller ve yazar notları bölümlerini içermelidir.

a) Başlık: En fazla 10-12 kelimeden oluşan makale başlığı (kelimeler arasındaki boşluklar ile beraber en fazla 50 karakter) bu sayfada yer almalıdır.

Yazar adı: Başlığın altına yazılmalı, görev ünvanı, kurum adresi ve e-posta bilgileri bir yıldızla soyadına ilintilendirilerek, ilk sayfanın altında verilmelidir.

b) Özet ve anahtar kelimeler: Özet, Türkçe ve İngilizce olmak üzere her iki dilde 'ÖZET' ve 'ABSTRACT' başlıkları altında 200 kelimeyi geçmeyecek şekilde olmalıdır. Anahtar kelimeler (3 ile 10 arasında) Türkçe özetin altında 'Anahtar kelimeler' ve İngilizce özetin altında 'Keywords' başlığı kullanılarak verilmelidir. Türkçe ve İngilizce özetin her biri yeni bir sayfadan başlamalıdır.

c) Ana metin: Yeni bir sayfadan başlamalıdır. Görgül makalelerde metin, sırasıyla giriş, yöntem, bulgular ve tartışma bölümlerinden oluşmalıdır. Derleme türü makalelerde, makalenin içeriğine bağlı olarak bu sıra değişebilir. Kısa başlık her sayfanın sağ köşesinde, yanında sayfa numarası olacak şekilde tekrarlanmalıdır. Makalenin başlığı ana metnin ilk sayfasında yer almalı ve başlıktan sonra, "Giriş" alt başlığı yazılmadan paragraf ile metne başlanmalıdır. Yöntem, Bulgular ve Tartışma bölümleri yeni bir sayfadan başlamamalıdır; bir bölüm bittikten sonra, diğeri onu aynı sayfada izlemelidir.

Giriş bölümü, yapılan araştırma ile ilgili olarak, alanyazındaki yaklaşım ve bulgular ile araştırmanın amacını içermelidir. Yöntem bölümü örneklem, veri toplama araçları ve işlem olmak üzere 3 alt bölümden oluşmalıdır. Bulgular araştırmanın denencelerini test etmek amacı ile kullanılan istatistiksel analizleri, her değişkene ait ortalama ve standart sapma değerlerini içermelidir. Tablolar ve şekiller ayrı bir sayfada yazının en sonunda verilmelidir. Verilecek olan tablolarda ortalamalar "Ort." şeklinde, standart sapmalar ise "ss" şeklinde gösterilmelidir.

Tartışma bölümü, araştırma bulgularının alanyazın ışığında açıklanmasını, tartışılmasını içermelidir.

d) Kaynaklar: Yeni bir sayfadan başlamalıdır. Metin içinde belirtilen tüm kaynaklar 'Kaynaklar' listesi içinde yer almalıdır.

Metin içinde kaynaklara atıfta bulunurken yazarların soyadları ve yayın tarihi kullanılır.

Örnekler:

Köksal (2011) ...

Köksal' a (2011) göre ...

Dils ve Boroditsky (2010) ...

Dills ve Boroditsky’a (2010) göre ... 
Yazar sayısı 3 ile 5 arasında ise, metin içinde ilk geçtiği yerde yukarıda olduğu gibi verilir; yazar sayısı 6 veya daha fazla ise metin içinde ilk geçtiği yerden itibaren 'Stallard ve arkadaşları (2010)' olarak verilmelidir. Cümle sonunda birden fazla esere atıfta bulunuluyor ise kaynaklar parantez içinde alfabetik sıra ile verilmelidir

... (Baggerly ve Exum, 2008; Gil,1991; Landreth, 2002).

Kaynaklar bölümünde kaynaklar alfabetik sıra ile verilmelidir.

e) Ekler: Yeni bir sayfadan başlamalıdır. Araştırmada kullanılan ölçekler bu bölümde yer almalidir.

f) Tablolar: Yeni bir sayfadan başlamalı ve her bir tablo ayrı bir sayfada verilmedir. Tablo numarası ve Tablo başlığı tablonun üstünde kelimelerin baş harfleri büyük olarak yer almalıdır. Gönderilecek olan tablolar mutlaka Word programının "Tablo" seçeneği kullanılarak hazırlanmalıdır.

g) Şekil başlıkları ve şekiller: Yeni bir sayfadan başlamalıdır. Şekil numarası ve şekil başlıkları kelimelerin baş harfleri büyük olarak aynı sayfada alt alta verilmelidir. Şekillerin her biri ise ayrı sayfalarda verilmelidir. Gönderilecek olan tablolar ve şekillerin toplam sayısının 5 ya da 6'yı geçmemesine özen gösterilmelidir.

h) Yazar notları: Yeni bir sayfadan başlamalıdır. Eğer araştırma bir tez çalışmasının özeti ise veya araştırmayı destekleyen kurum(lar) var ise bu bölümde belirtilmelidir. Ayrıca araştırmacının, araştırmaya katkılarından dolayı teşekkür etmek istediği kişiler de bu sayfada belirtilmelidir.

4. Yazılardan ifade edilen düşüncelerden yazarları sorumludur.

5. NPD' de yayınlarından ancak kaynak gösterilerek alıntı yapılabilir. Yazının içeriğinde olabilecek çarpıtmalardan alıntıyı yapan ve yayınlayan kişi ya da kuruluşlar yasalar karşısında sorumludur.

6. Yayın Kurulu, yazıda gerekli gördüğü sözcükleri değiştirebilir.

7. Kurallara uymayan yazılar yayınlanmaz.

8. NPD’ de yayınlanan yazılar için herhangi bir telif ücreti ödenmez.

9. Yayınlanan her araştırmanın verilerinin 5 yıl süre ile araştırmacı tarafından saklanması zorunludur. Gerek yayın politikamız gerekse uluslararası yayın kuruluşlarının kuralları gereğince zaman zaman bazı yazıların verileri ve analiz programları yazarlarından istenebilecektir. 


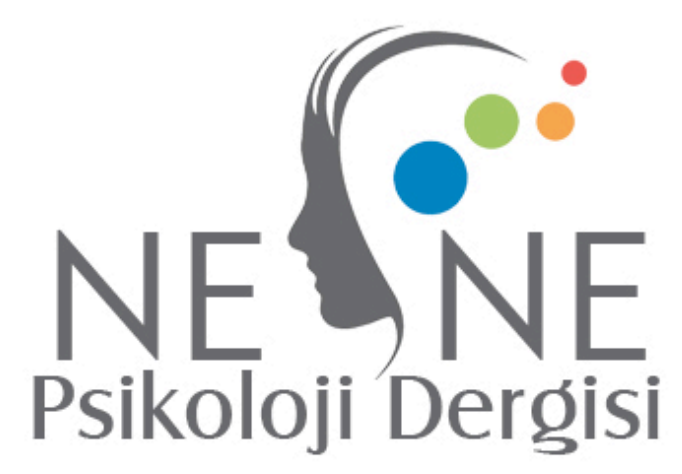

ISSN: 2147- 6489 Sayı/Number:1 Yaz/Spring 2013

İÇINDEKILER / CONTENTS

BİR KELIME NEYİ DEĞISSTIIRIR? BOYUT DEĞİSTTIREREK EŞLEME GÖREVINE KAVRAMSAL AĞLARIN ETKİSI / Tolga YILDIZ 1

ERGENLERDE BAĞLANMA VE SALDIRGANLIK DAVRANIŞLARI

ARASINDAKİ İLIŞKINININ İNCELENMESİ /

Bilge KAPLAN ve Eda Şeyda AKSEL 20

ÖNYARGILARIN PSIKOLOJISİ: PSIKODINAMIK BİR GÖZDEN

GEÇİRME / Rifat S. İLHAN ve Abdülkadir ÇEVİK .50

PROF. DR. ALİ DÖNMEZ İLE SOSYAL PSIKOLOJI ÜZERINE Söyleşi: Melik ÇELIIK ve Sezin ANDİÇ .68

ORGANIK ÇOCUKLAR-1 KITAP TANITIMI

Tanıtan: Serap ERDOĞAN .72 